\title{
A solution of the fractional differential equations in the setting of $b$-metric space
}

\author{
Afshari H. ${ }^{1}$, Karapınar E. ${ }^{2,3,4}$ \\ In this paper, we study the existence of solutions for the following differential equations by using \\ a fixed point theorems

$$
\left\{\begin{array}{l}
D_{c}^{\mu} w(\varsigma) \pm D_{c}^{v} w(\varsigma)=h(\varsigma, w(\varsigma)), \quad \varsigma \in J, \quad 0<v<\mu<1, \\
w(0)=w_{0}
\end{array}\right.
$$ \\ where $D^{\mu}, D^{v}$ is the Caputo derivative of order $\mu, v$, respectively and $h: J \times \mathbb{R} \rightarrow \mathbb{R}$ is continuous. \\ The results are well demonstrated with the aid of exciting examples. \\ Key words and phrases: complete $b$-metric space, Caputo derivative, $\alpha-\psi$-Geraghty contractive \\ type mapping.

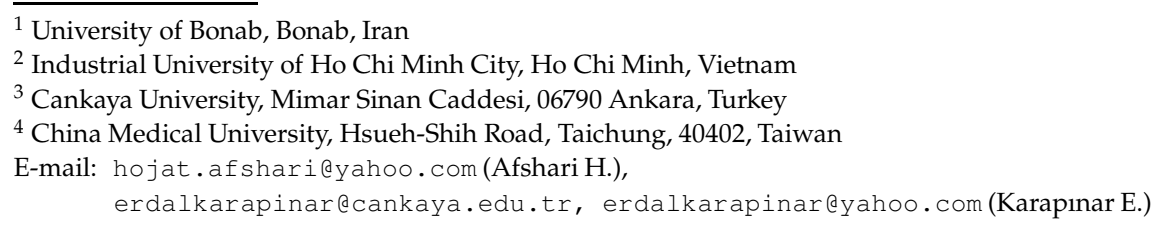

\section{Introduction}

In 2012, E. Karapınar and B. Samet introduced generalized $\alpha$ - $\psi$-contractive type mappings to combine several fixed point theorems that were focused on "fixed point results via cycliccontraction" and "fixed point theorems over partially ordered set". Several authors developed this trend (see, e.g. $[2,11,12,24,27,30])$. Among all, in [6,7], the authors considered generalized $\alpha-\psi$-Geraghty contractive mappings in the context of complete $b$-metric spaces.

In the last few years, fractional calculus concepts were frequently applied to other disciplines, especially dealing with physical phenomena. In most of the available literature, fractional integral equations play an essential role in the qualitative analysis of the solutions for fractional differential equations (see, e.g. $[18,26]$ ). Very recently, H. Afshari, S. Kalantari and E. Karapınar [7] investigated the existence of solutions for some fractional differential equations in metric and $b$-metric spaces. Indeed, this trend in distinct abstract spaces has been investigated by a number of authors (see, e.g. [1,3-5, 8-10,13-17,19-23]).

Based on a fixed point theorem, we study the following equations

$$
\left\{\begin{array}{l}
D_{c}^{\mu} w(\varsigma) \pm D_{c}^{v} w(\varsigma)=h(\varsigma, w(\varsigma)), \quad \varsigma \in[0,1], \quad 0<v<\mu<1, \\
w(0)=w_{0}
\end{array}\right.
$$

where $D^{\mu}, D^{v}$ are the Caputo derivatives of order $\mu, v$, respectively. 
Throughout the article, $J$ denotes the closed unit interval, i.e. $[0,1]$.

Definition 1 ( $[25,29])$. Assume that $h:[0, \infty) \rightarrow \mathbb{R}$ is continuous. The Caputo derivative of order $\mu$ is defined by

$$
{ }^{c} D^{\mu} h(\varsigma)=\frac{1}{\lambda(n-\mu)} \int_{0}^{\varsigma}(\varsigma-\vartheta)^{n-\mu-1} h^{(n)}(\vartheta) d \vartheta, \quad n-1<\mu<n, \quad n \in \mathbb{N} .
$$

Definition 2 ( $[25,29])$. The Riemann-Lioville derivative of order $\mu$ for a continuous function $h$ is defined by

$$
D^{\mu} h(\varsigma)=\frac{1}{\lambda(n-\mu)}\left(\frac{d}{d \varsigma}\right)^{n} \int_{0}^{\varsigma} \frac{h(\vartheta)}{(\varsigma-\vartheta)^{\mu-n+1}} d \vartheta, \quad n-1<\mu<n, \quad n \in \mathbb{N} .
$$

Let $\Psi$ be set of all increasing and continuous functions $\psi:[0, \infty) \rightarrow[0, \infty)$ satisfying $\psi(c w) \leq c \psi(w) \leq c w$ for all $c>1$. Also $\Lambda$ is the family of all nondecreasing functions $\lambda:[0, \infty) \rightarrow\left[0,1 / s^{2}\right)$ for some $s \geq 1$.

Definition 3 ([7]). Let $(\mathrm{X}, d)$ be a $b$-metric space. A self-mapping $f: X \rightarrow X$ is called a generalized $\alpha-\psi$-Geraghty contraction type mapping whenever there exists $\alpha: X \times X \rightarrow[0, \infty)$ with

$$
\alpha(z, t) \psi\left(s^{3} d(f z, f t)\right) \leq \lambda(\psi(d(z, t))) \psi(d(z, t)),
$$

for all $z, t \in X$, where $\lambda \in \Lambda$ and $\psi \in \Psi$.

Definition 4 ([31]). Let $f: \mathrm{X} \rightarrow \mathrm{X}$ and $\alpha: \mathrm{X} \times \mathrm{X} \rightarrow[0, \infty)$ be given, where $\mathrm{X}$ is nonempty. We say that a mapping $f$ is $\alpha$-admissible if

$$
\alpha(z, t) \geq 1 \quad \Longrightarrow \quad \alpha(f z, f t) \geq 1,
$$

for all $z, t \in X$.

Theorem 1 ([7]). Let $(\mathrm{X}, d)$ be a complete $b$-metric space and $f: \mathrm{X} \rightarrow \mathrm{X}$ be a generalized $\alpha-\psi$-Geraghty contraction such that

(i) $f$ is $\alpha$-admissible;

(ii) there exists $u_{0} \in \mathrm{X}$ with $\alpha\left(u_{0}, f u_{0}\right) \geq 1$;

(iii) if $\left\{u_{n}\right\} \subseteq X, u_{n} \rightarrow u$ in $X$ and $\alpha\left(u_{n}, u_{n+1}\right) \geq 1$, then $\alpha\left(u_{n}, u\right) \geq 1$ for all $n$.

Then $f$ has a fixed point.

\section{Main result}

Throughout the paper, $X=C(J, \mathbb{R})$ will denote the set of continuous functions and $d: \mathrm{X} \times \mathrm{X} \rightarrow[0, \infty)$ given by

$$
d(w, z)=\left\|(w-z)^{2}\right\|_{\infty}=\sup _{\varsigma \in J}(w(\varsigma)-z(\varsigma))^{2}
$$

then the pair $(X, d)$ is a complete $b$-metric space with $s=2$, but $(X, d)$ is not metric space.

We consider the problem

$$
\left\{\begin{array}{l}
D_{c}^{\mu} w(\varsigma)-D_{c}^{v} w(\varsigma)=h(\varsigma, w(\varsigma)), \quad \varsigma \in J, \quad 0<v<\mu<1, \\
w(0)=w_{0},
\end{array}\right.
$$

where $D^{\mu}, D^{v}$ are the Caputo derivatives of order $\mu, v$, respectively, and $h: \mathbb{R}^{+} \times \mathbb{R} \rightarrow \mathbb{R}$ is continuous. 
Lemma 1 ( [32]). Let $h: \mathbb{R}^{+} \times \mathbb{R} \rightarrow \mathbb{R}$ be a continuous function. If $w(\cdot) \in C(J)$ and it is a solution of the following integral equation

$$
w(\varsigma)=w_{0}+\frac{1}{\lambda(\mu-v)} \int_{0}^{\varsigma}(\varsigma-\vartheta)^{\mu-v-1}\left(w(\vartheta)-w_{0}\right) d \vartheta+\frac{1}{\lambda(\mu)} \int_{0}^{\varsigma}(\varsigma-\vartheta)^{\mu-1} h(\vartheta, w(\vartheta)) d \vartheta,
$$

then $w(\varsigma)$ is a solution of the fractional integral equation (1).

Theorem 2. Suppose that:

(i) there exists $\phi: \mathbb{R}^{2} \rightarrow \mathbb{R}$ such that

$$
|h(\varsigma, w)-h(\varsigma, z)| \leq|w-z|\left(\frac{\mu-v}{2 \sqrt{2}} \lambda(\mu-v) \sqrt{\lambda\left(\|w-z\|_{\infty}^{2}\right)}-1\right),
$$

for any $\varsigma \in J$;

(ii) there exists $w_{0} \in C(J)$ such that $\phi\left(w_{0}(\varsigma), A w_{0}(\varsigma)\right) \geq 0$ for all $\varsigma \in J$, where the operator $A: C(J) \rightarrow C(J)$ is defined by

$$
\begin{aligned}
A w(\varsigma)=w_{0} & +\frac{1}{\lambda(\mu-v)} \int_{0}^{\varsigma}(\varsigma-\vartheta)^{\mu-v-1}\left(w(\vartheta)-w_{0}\right) d \vartheta \\
& +\frac{1}{\lambda(\mu)} \int_{0}^{\varsigma}(\varsigma-\vartheta)^{\mu-1} h(\vartheta, w(\vartheta)) d \vartheta
\end{aligned}
$$

(iii) for all $\varsigma \in J$ and $w, z \in C(J), \phi(w(\varsigma), z(\varsigma)) \geq 0$ implies $\phi(A w(\varsigma), A z(\varsigma)) \geq 0$;

(iv) if $\left\{w_{n}\right\} \subseteq C(J), w_{n} \rightarrow w$ in $C(J)$, and $\phi\left(w_{n}, w_{n+1}\right) \geq 0$, then $\phi\left(w_{n}, w\right) \geq 0$ for all $n$.

Then the problem (1) has at least one solution.

Proof. By Lemma $1 w \in C(J)$ is a solution of (1) if it is a solution of the following

$$
w(\varsigma)=w_{0}+\frac{1}{\lambda(\mu-v)} \int_{0}^{\varsigma}(\varsigma-\vartheta)^{\mu-v-1}\left(w(\vartheta)-w_{0}\right) d \vartheta+\frac{1}{\lambda(\mu)} \int_{0}^{\varsigma}(\varsigma-\vartheta)^{\mu-1} h(\vartheta, w(\vartheta)) d \vartheta
$$

Then, the problem (1) is equivalent to finding a fixed point of $A$. Let $w, z \in C(J)$ be with $\phi(w(\varsigma), z(\varsigma)) \geq 0$ for all $\varsigma \in J$. Using (i), we get

$$
\begin{aligned}
\mid A w(\varsigma)- & \left.A z(\varsigma)\right|^{2}=\mid \frac{1}{\lambda(\mu-v)} \int_{0}^{\varsigma}(\varsigma-\vartheta)^{\mu-v-1}(w(\vartheta)-z(\vartheta)) d \vartheta \\
& \quad+\left.\frac{1}{\lambda(\mu)} \int_{0}^{\varsigma}(\varsigma-\vartheta)^{\mu-1}(h(\vartheta, w(\vartheta))-h(\vartheta, z(\vartheta))) d \vartheta\right|^{2} \\
\leq & \left|\frac{1}{\lambda(\mu-v)} \int_{0}^{\varsigma}(\varsigma-\vartheta)^{\mu-v-1}(|w(\vartheta)-z(\vartheta)|+|h(\vartheta, w(\vartheta))-h(\vartheta, z(\vartheta))|) d \vartheta\right|^{2} \\
\leq & \mid \frac{1}{\lambda(\mu-v)} \int_{0}^{\varsigma}(\varsigma-\vartheta)^{\mu-v-1} \\
& \quad \times\left.\left[|w(\vartheta)-z(\vartheta)|+|w(\vartheta)-z(\vartheta)|\left(\frac{\mu-v}{2 \sqrt{2}} \lambda(\mu-v) \sqrt{\lambda\left(\|w-z\|_{\infty}^{2}\right)}-1\right)\right] d \vartheta\right|^{2} \\
\leq & \left|\frac{1}{\lambda(\mu-v)} \int_{0}^{\varsigma}\left((\varsigma-\vartheta)^{\mu-v-1}|w(\vartheta)-z(\vartheta)| \frac{\mu-v}{2 \sqrt{2}} \lambda(\mu-v) \sqrt{\lambda\left(\|w-z\|_{\infty}^{2}\right)}\right) d \vartheta\right|^{2} \\
\leq & \frac{1}{8}\|w(\vartheta)-z(\vartheta)\|_{\infty}^{2} \lambda\left(\|w-z\|_{\infty}^{2}\right) .
\end{aligned}
$$


Therefore for $w, z \in C(J), \varsigma \in J$ with $\phi(w(\varsigma), z(\varsigma)) \geq 0$, we have

$$
\left\|(A w-A z)^{2}\right\|_{\infty} \leq \frac{1}{8}\|w(\vartheta)-z(\vartheta)\|_{\infty}^{2} \lambda\left(\|w-z\|_{\infty}^{2}\right) .
$$

Define $\alpha: C(J) \times C(J) \rightarrow[0, \infty)$ by

$$
\alpha(w, z)= \begin{cases}1, & \phi(w(\varsigma), z(\varsigma)) \geq 0 \quad \text { for all } \quad \varsigma \in J \\ 0, & \text { otherwise }\end{cases}
$$

So,

$$
\alpha(w, z) 8 d(A w, A z) \leq 8 d(A w, A z) \leq \lambda(d(w, z) d(w, z), \quad \lambda \in \Lambda
$$

From (iii),

$$
\alpha(w, z) \geq 1 \Rightarrow \phi(w(\varsigma), z(\varsigma)) \geq 0 \Rightarrow \phi(A(w), A(z)) \geq 0 \quad \Rightarrow \quad \alpha(A(w), A(z)) \geq 1
$$

for all $w, z \in C(J)$. Thus, $A$ is $\alpha$-admissible. From (ii), it follows that there exists $w_{0} \in C(J)$ with $\alpha\left(w_{0}, A w_{0}\right) \geq 1$. By (iv) and Theorem 1, we find out $w^{*}$ with $w^{*}=A w^{*}$, that is a solution of the problem.

By taking $\lambda(t)=s /(4 s+1)$ (it is clear that $\lambda \in \Lambda$ ) in Theorem 2, we instantly obtain the following result.

Corollary 1. Suppose that:

(i) there exists $\phi: \mathbb{R}^{2} \rightarrow \mathbb{R}$ such that

$$
|h(\zeta, w)-h(\varsigma, z)| \leq \frac{\mu-v}{2 \sqrt{2}}|w-z|\left(\lambda(\mu-v) \sqrt{\frac{\|w-z\|_{\infty}^{2}}{4\|w-z\|_{\infty}^{2}+1}}-1\right),
$$

for any $\varsigma \in J$ and $w, z \in \mathbb{R}$;

(ii) there exists $w_{0} \in C(J)$ such that $\phi\left(w_{0}(\varsigma), A w_{0}(\varsigma)\right) \geq 0$ for all $\varsigma \in J$, where the operator $A: C(J) \rightarrow C(J)$ is defined by

$$
A w(\varsigma)=\frac{1}{\lambda(\mu-v)} \int_{0}^{\varsigma}(\varsigma-\vartheta)^{\mu-v-1}(w(\vartheta)) d \vartheta+\frac{1}{\lambda(\mu)} \int_{0}^{\varsigma}(\varsigma-\vartheta)^{\mu-1} h(\vartheta, w(\vartheta)) d \vartheta
$$

(iii) for all $\varsigma \in J$ and $w, z \in C(J), \phi(w(\varsigma), z(\varsigma)) \geq 0$ implies $\phi(A w(\varsigma), A z(\varsigma)) \geq 0$;

(iv) if $\left\{w_{n}\right\} \subseteq C(J), w_{n} \rightarrow w$ in $C(J)$ and $\phi\left(w_{n}, w_{n+1}\right) \geq 0$, then $\phi\left(w_{n}, w\right) \geq 0$ for all $n$.

Then the problem (1) has at least one solution.

We study now the nonlinear fractional differential equation

$$
\left\{\begin{array}{l}
D_{c}^{\mu} w(\varsigma)+D_{c}^{v} w(\varsigma)=h(\varsigma, w(\varsigma)), \quad \varsigma \in J, \quad 0<v<\mu<1, \\
w(0)=w(1)=0
\end{array}\right.
$$

where $h: J \times \mathbb{R} \rightarrow \mathbb{R}$ is a continuous function. Recall that the Green function associated with (2) is given by $\mathbb{G}(t)=t^{\mu-1} E_{\mu-v}\left(-t^{\mu-v}\right)$. 
Theorem 3. Suppose that:

(i) there exist $\phi: \mathbb{R}^{2} \rightarrow \mathbb{R}$ and $\psi \in \Psi$ such that

$$
|h(\varsigma, w)-h(\varsigma, z)| \leq \frac{\mu}{2 \sqrt{2}} \sqrt{\psi\left(\left\|(w-z)^{2}\right\|_{\infty}\right) \lambda\left(\psi\left(\left\|(w-z)^{2}\right\|_{\infty}\right)\right)},
$$

for any $\varsigma \in J$ and $w, z \in \mathbb{R}$;

(ii) there exists $w_{0} \in C(J)$ such that

$$
\phi\left(w_{0}(\varsigma), \int_{0}^{1} \mathbb{G}(\varsigma, \vartheta) h\left(\vartheta, w_{0}(\vartheta)\right) d \vartheta\right) \geq 0 \quad \text { for all } \quad \varsigma \in J
$$

(iii) for all $\varsigma \in J$ and $w, z \in C(J), \phi(w(\varsigma), z(\varsigma)) \geq 0$ implies

$$
\phi\left(\int_{0}^{1} \mathbb{G}(\varsigma, \vartheta) h(\vartheta, w(\vartheta)) d \vartheta, \int_{0}^{1} \mathbb{G}(\zeta, \vartheta) h(\vartheta, z(\vartheta)) d \vartheta\right) \geq 0
$$

(iv) if $\left\{w_{n}\right\} \subseteq C(J), w_{n} \rightarrow w$ in $C(J)$, and $\phi\left(w_{n}, w_{n+1}\right) \geq 0$, then $\phi\left(w_{n}, w\right) \geq 0$ for all $n$.

Then the problem (2) has at least one solution.

Proof. It is well known that $w \in C(J)$ is a solution of (2) if and only if it is a solution of the integral equation

$$
w(\varsigma)=\int_{0}^{\varsigma} \mathbb{G}(\varsigma-\vartheta) h(\vartheta, w(\vartheta)) d \vartheta \quad \text { for all } \quad \varsigma \in J .
$$

Define the operator $F: C(J) \rightarrow C(J)$ by

$$
F w(\varsigma)=\int_{0}^{\varsigma} \mathbb{G}(\varsigma-\vartheta) h(\vartheta, w(\vartheta)) d \vartheta \quad \text { for all } \quad \varsigma \in J .
$$

Thus, for finding a solution of the problem (2), it is sufficient to find a fixed point of $F$. Now, let $w, z \in C(J)$ be such that $\varsigma(w(\varsigma), y(t)) \geq 0$ for all $\varsigma \in J$. Using (i), we get

$$
\begin{aligned}
|A w(\varsigma)-A z(\varsigma)|^{2} & \leq\left[\int_{0}^{1} \mathbb{G}(\varsigma-\vartheta)|h(\vartheta, w(\vartheta))-h(\vartheta, z(\vartheta))| d \vartheta\right]^{2} \\
& \leq\left[\int_{0}^{1} \mathbb{G}(\varsigma-\vartheta) \frac{\mu}{2 \sqrt{2}} \sqrt{\psi\left(\left\|(w-z)^{2}\right\|_{\infty}\right) \lambda\left(\psi\left(\left\|(w-z)^{2}\right\|_{\infty}\right)\right)} d \vartheta\right]^{2} \\
& \leq \frac{1}{8} \psi\left(\left\|(w-z)^{2}\right\|_{\infty}\right) \lambda\left(\psi\left(\left\|(w-z)^{2}\right\|_{\infty}\right)\right) .
\end{aligned}
$$

The rest of the proof is similar to Theorem 2 .

In Theorem 3, with setting $\lambda(s)=s /(4 s+1)$ (it is clear that $\lambda \in \Lambda$ ) we can deduce the following conclusion.

Corollary 2. Suppose that:

(i) there exist $\phi: \mathbb{R}^{2} \rightarrow \mathbb{R}$ and $\psi \in \Psi$ such that

$$
|h(\varsigma, w)-h(\varsigma, z)| \leq \frac{\mu}{2 \sqrt{2}} \frac{\psi\left(\left\|(w-z)^{2}\right\|_{\infty}\right)}{\sqrt{4 \psi\left(\left\|(w-z)^{2}\right\|_{\infty}\right)+1}},
$$

for any $\varsigma \in J$ and $w, z \in \mathbb{R}$; 
(ii) there exists $w_{0} \in C(J)$ such that

$$
\phi\left(w_{0}(\varsigma), \int_{0}^{1} \mathbb{G}(\varsigma, \vartheta) h\left(\vartheta, w_{0}(\vartheta)\right) d \vartheta\right) \geq 0 \quad \text { for all } \quad \varsigma \in J ;
$$

(iii) for all $\varsigma \in J$ and $w, z \in C(J), \phi(w(\varsigma), z(\varsigma)) \geq 0$ implies

$$
\phi\left(\int_{0}^{1} \mathbb{G}(\zeta, \vartheta) h(\vartheta, w(\vartheta)) d \vartheta, \int_{0}^{1} \mathbb{G}(\zeta, \vartheta) h(\vartheta, z(\vartheta)) d \vartheta\right) \geq 0
$$

(iv) if $\left\{w_{n}\right\} \subseteq C(J), w_{n} \rightarrow w$ in $C(J)$, and $\phi\left(w_{n}, w_{n+1}\right) \geq 0$, then $\phi\left(w_{n}, w\right) \geq 0$ for all $n$.

Then the problem (2) has at least one solution.

Remark 1. In Corollary 2 instead of inequality (3), we can use the following inequality

$$
|h(\varsigma, w)-h(\varsigma, z)| \leq \frac{\mu}{2 \sqrt{2}} \frac{\psi\left(\left\|(w-z)^{2}\right\|_{\infty}\right)}{\sqrt{4\left\|(w-z)^{2}\right\|_{\infty}+1}},
$$

because by considering $\psi(\varsigma)<\varsigma$, we get

$$
|h(\varsigma, w)-h(\varsigma, z)| \leq \frac{\mu}{2 \sqrt{2}} \frac{\psi\left(\left\|(w-z)^{2}\right\|_{\infty}\right)}{\sqrt{4\left\|(w-z)^{2}\right\|_{\infty}+1}} \leq \frac{\mu}{2 \sqrt{2}} \frac{\psi\left(\left\|(w-z)^{2}\right\|_{\infty}\right)}{\sqrt{\psi\left(4\left\|(w-z)^{2}\right\|_{\infty}\right)+1}} .
$$

Example 1. Let $\mathrm{X}=C(J)$ be endowed with

$$
d(w, z)=\left\|(w-z)^{2}\right\|_{\infty}=\sup _{\varsigma \in J}(w(\varsigma)-z(\varsigma))^{2} .
$$

Let $\psi(\varsigma)=4 \sqrt{2 \varsigma(1+4 \varsigma)}, \phi(w, z)=w z$ and $w_{n}(\varsigma)=\varsigma n^{4} /\left(n^{4}+n^{2}\right)$. We consider the following problem

$$
\left\{\begin{array}{l}
D_{c}^{1 / 2} w(\varsigma)+D_{c}^{1 / 4} w(\varsigma)=\varsigma^{2} w(\varsigma), \quad 0 \leq \varsigma \leq 1, \\
w(0)=w(1)=0
\end{array}\right.
$$

here $h(\varsigma, w(\varsigma))=\varsigma^{2} w(\varsigma)$ and we have

$$
\begin{aligned}
|h(\varsigma, w(\varsigma))-h(\varsigma, z(\varsigma))|^{2} & =\varsigma^{4}|w(\varsigma)-z(\varsigma)|^{2} \leq\left\|(w-z)^{2}\right\|_{\infty} \\
& =\left\|(w-z)^{2}\right\|_{\infty} \frac{32}{32} \frac{4\left\|(w-z)^{2}\right\|_{\infty}+1}{4\left\|(w-z)^{2}\right\|_{\infty}+1}=\frac{\psi\left(\left\|(w-z)^{2}\right\|_{\infty}\right)^{2}}{32\left(4\left\|(w-z)^{2}\right\|_{\infty}+1\right)},
\end{aligned}
$$

hence

$$
|h(\varsigma, w(\varsigma))-h(\varsigma, z(\varsigma))| \leq \frac{\psi\left(\left\|(w-z)^{2}\right\|_{\infty}\right)}{4 \sqrt{2\left(4\left\|(w-z)^{2}\right\|_{\infty}+1\right)}}=\frac{\mu}{2 \sqrt{2}} \frac{\psi\left(\left\|(w-z)^{2}\right\|_{\infty}\right)}{\sqrt{4\left\|(w-z)^{2}\right\|_{\infty}+1}} .
$$

So, the condition (i) of Corollary 2 by Remark 1 is satisfied.

If $w_{0}(\varsigma)=\varsigma$, then

$$
\phi\left(w_{0}(\varsigma), \int_{0}^{1} \mathbb{G}(\varsigma, \vartheta) h\left(\vartheta, w_{0}(\vartheta)\right) d \vartheta\right) \geq 0,
$$

for all $\varsigma \in J$. Also, $\phi(w(\varsigma), z(\varsigma))=w(\varsigma) z(\varsigma) \geq 0$ implies that

$$
\phi\left(\int_{0}^{1} \mathbb{G}(\varsigma, \vartheta) h\left(\varsigma, w_{(\varsigma)}\right) d \varsigma, \int_{0}^{1} \mathbb{G}(\varsigma, \vartheta) h(\vartheta, z(\vartheta)) d \vartheta\right) \geq 0
$$

It is clear that condition (iii) in Corollary 2 holds. Hence, from Corollary 2 the problem (4) has at least one solution. 
If we put $\lambda(s)=s^{2}+1 /\left(4 s^{2}+8\right)$ (it is clear that $\lambda \in \Lambda$ ) in Theorem 3 , we may state the following result.

Corollary 3. Suppose that:

(i) there exist $\phi: \mathbb{R}^{2} \rightarrow \mathbb{R}$ and $\psi \in \Psi$ such that

$$
|h(\varsigma, w)-h(\varsigma, z)| \leq \frac{\mu}{2 \sqrt{2}} \sqrt{\frac{\psi\left(\left\|(w-z)^{2}\right\|_{\infty}\right)\left(\left(\psi\left(\left\|(w-z)^{2}\right\|_{\infty}\right)\right)^{2}+1\right)}{4\left(\psi\left(\left\|(w-z)^{2}\right\|_{\infty}\right)\right)^{2}+8}},
$$

for any $\varsigma \in J$ and $w, z \in \mathbb{R}$;

(ii) there exists $w_{0} \in C(J)$ such that

$$
\phi\left(w_{0}(\varsigma), \int_{0}^{1} \mathbb{G}(\varsigma, \vartheta) h\left(\vartheta, w_{0}(\vartheta)\right) d \vartheta\right) \geq 0 \quad \text { for all } \quad \varsigma \in J ;
$$

(iii) for all $\varsigma \in J$ and $w, z \in C(J), \phi(w(\varsigma), z(\varsigma)) \geq 0$ implies

$$
\phi\left(\int_{0}^{1} \mathbb{G}(\zeta, \vartheta) h(\vartheta, w(\vartheta)) d \vartheta, \int_{0}^{1} \mathbb{G}(\zeta, \vartheta) h(\vartheta, z(\vartheta)) d \vartheta\right) \geq 0
$$

(iv) if $\left\{w_{n}\right\} \subseteq C(J), w_{n} \rightarrow w$ in $C(J)$, and $\phi\left(w_{n}, w_{n+1}\right) \geq 0$ then $\phi\left(w_{n}, w\right) \geq 0$ for all $n$.

Then the problem (2) has at least one solution.

Remark 2. In Corollary 3 instead of inequality (5), we can use the following inequality

$$
|h(\varsigma, w)-h(\varsigma, z)| \leq \frac{\mu}{2 \sqrt{2}} \sqrt{\frac{\psi\left(\left\|(w-z)^{2}\right\|_{\infty}\right)\left(\left(\psi\left(\left\|(w-z)^{2}\right\|_{\infty}\right)\right)^{2}+1\right)}{4\left(\left\|(w-z)^{2}\right\|_{\infty}\right)^{2}+8}},
$$

because by considering $\psi(\varsigma)<\varsigma$, we get

$$
\begin{aligned}
|h(\zeta, w)-h(\zeta, z)| & \leq \sqrt{\frac{\psi\left(\left\|(w-z)^{2}\right\|_{\infty}\right)\left(\left(\psi\left(\left\|(w-z)^{2}\right\|_{\infty}\right)\right)^{2}+1\right)}{4\left(\left\|(w-z)^{2}\right\|_{\infty}\right)^{2}+8}} \\
& \leq \frac{\mu}{2 \sqrt{2}} \sqrt{\frac{\psi\left(\left\|(w-z)^{2}\right\|_{\infty}\right)\left(\left(\psi\left(\left\|(w-z)^{2}\right\|_{\infty}\right)\right)^{2}+1\right)}{4\left(\psi\left(\left\|(w-z)^{2}\right\|_{\infty}\right)\right)^{2}+8}} .
\end{aligned}
$$

Example 2. Let $X=C(J)$ be endowed with the following norm

$$
d(w, z)=\left\|(w-z)^{2}\right\|_{\infty}=\sup _{\varsigma \in J}(w(\varsigma)-z(\varsigma))^{2},
$$

also $\psi(\varsigma)=\varsigma, \phi(w, z)=w z$ and $w_{n}(\varsigma)=\varsigma /\left(n^{4}+1\right)$. We consider the following periodic boundary value problem

$$
\left\{\begin{array}{l}
D_{c}^{1 / 2} w(\varsigma)+D_{c}^{1 / 4} w(\varsigma)=\varsigma^{2} f(w(\varsigma)), \quad 0 \leq \varsigma \leq 1 \\
w(0)=w(1)=0
\end{array}\right.
$$

where $f$ satisfies the condition

$$
|f(w)-f(w)|^{2} \leq \frac{|w-z|^{2}}{128\left(|w-z|^{2}+2\right)}
$$


for all $w, z \in C(J)$. We have

$$
\begin{aligned}
|h(\varsigma, w(\varsigma))-h(\varsigma, z(\varsigma))|^{2} & =\varsigma^{4}|f(w(\varsigma))-f(z(\varsigma))|^{2} \\
& \leq|f(w(\varsigma))-f(z(\varsigma))|^{2} \leq \frac{|w(\varsigma)-z(\varsigma)|^{2}}{128\left(|w(\varsigma)-z(\varsigma)|^{2}+2\right)} \\
& \leq \frac{1}{32} \frac{\left\|(w(\varsigma)-z(\varsigma))^{2}\right\|_{\infty}\left(\left(\left\|(w(\varsigma)-z(\varsigma))^{2}\right\|_{\infty}\right)^{2}+1\right)}{4\left(\left\|(w(\varsigma)-z(\varsigma))^{2}\right\|_{\infty}\right)^{2}+8} \\
& \leq \frac{\mu^{2}}{8} \frac{\psi\left(\left\|(w-z)^{2}\right\|_{\infty}\right)\left(\left(\psi\left(\left\|(w-z)^{2}\right\|_{\infty}\right)\right)^{2}+1\right)}{4\left(\psi\left(\left\|(w-z)^{2}\right\|_{\infty}\right)\right)^{2}+8} .
\end{aligned}
$$

Hence, we have

$$
|h(\zeta, w(\varsigma))-h(\zeta, z(\varsigma))| \leq \frac{\mu}{2 \sqrt{2}} \sqrt{\frac{\psi\left(\left\|(w-z)^{2}\right\|_{\infty}\right)\left(\left(\psi\left(\left\|(w-z)^{2}\right\|_{\infty}\right)\right)^{2}+1\right)}{4\left(\psi\left(\left\|(w-z)^{2}\right\|_{\infty}\right)\right)^{2}+8}} .
$$

So, the condition (i) of Corollary 3 by Remark 2 is clearly true.

If $w_{0}(\varsigma)=\varsigma$, then

$$
\phi\left(w_{0}(\varsigma), \int_{0}^{1} \mathbb{G}(\varsigma, \vartheta) h\left(\vartheta, w_{0}(\vartheta)\right) d \vartheta\right) \geq 0,
$$

for all $\varsigma \in J$. Also, $\phi(w(\varsigma), z(\varsigma))=w(\varsigma) z(\varsigma) \geq 0$ implies that

$$
\phi\left(\int_{0}^{1} \mathbb{G}(\zeta, \vartheta) h(\vartheta, w(\vartheta)) d \vartheta, \int_{0}^{1} \mathbb{G}(\zeta, \vartheta) h(\vartheta, z(\vartheta)) d \vartheta\right) \geq 0
$$

The condition (iii) in Corollary 3 is clearly true. Hence, by Corollary 3, we deduce that (6) has at least one solution.

In what follows, we consider the following fractional boundary value problem

$$
\left\{\begin{array}{l}
D_{0}^{v}=h(\varrho, y(\varrho)), \quad 0 \leq \varrho \leq 1, \quad 1<v<2 \\
y(0)=0, \quad D_{0}^{v-1} y(1)=0
\end{array}\right.
$$

The fractional boundary value problem (7) is equivalent to a Fredholm integral equation of the second kind

$$
y(\varrho)=\int_{0}^{1} \mathbb{G}(\varrho, \varsigma) h(\varsigma, y(\varsigma)) d \varsigma,
$$

where $h:[0 ; 1] \times \mathbb{R} \rightarrow \mathbb{R}$ is continuous and

$$
\mathbb{G}(\varrho, \varsigma)= \begin{cases}\varrho^{v-1} / \Gamma(v), & 0 \leq \varrho \leq \varsigma \leq 1 \\ \left((\varrho-\varsigma)^{v-1}-\varrho^{v-1}\right) / \Gamma(v), & 0 \leq \varsigma \leq \varrho \leq 1\end{cases}
$$

The function $\mathbb{G}(\varrho, \varsigma)$ has the following properties (see [28]):

(i) $\mathrm{G}(\varrho, \varsigma)<0,(\varrho, \varsigma) \in J \times J$;

(ii) $\max _{0 \leq t \leq 1}|\mathbb{G}(\varrho, \varsigma)|=|\mathbb{G}(\varsigma, \varsigma)|=\frac{\varsigma^{v-1}}{\Gamma(v)}, \quad \varsigma \in(0,1)$;

(iii)

$$
\max _{0 \leq t \leq 1} \int_{0}^{1}|G(\varrho, \varsigma) d \varsigma| \leq \frac{1}{\Gamma(v)} \int_{0}^{1} \varsigma^{\nu-1} d \varsigma=\frac{1}{\Gamma(v+1)}
$$


Theorem 4. Suppose that:

(i) there exist $\phi: \mathbb{R}^{2} \rightarrow \mathbb{R}$ and $\psi \in \Psi$ such that

$$
|h(\varsigma, w)-h(\varsigma, z)| \leq \frac{\Gamma(v+1)}{2 \sqrt{2}} \sqrt{\psi\left(\left\|(w-z)^{2}\right\|_{\infty}\right) \lambda\left(\psi\left(\left\|(w-z)^{2}\right\|_{\infty}\right)\right)}
$$

for any $\varsigma \in J$ and $w, z \in \mathbb{R}$;

(ii) there exists $w_{0} \in C(J)$ such that

$$
\phi\left(w_{0}(\varsigma), \int_{0}^{1} \mathbb{G}(\varsigma, \vartheta) h\left(\vartheta, w_{0}(\vartheta)\right) d \vartheta\right) \geq 0 \quad \text { for all } \quad \varsigma \in J
$$

(iii) for all $\varsigma \in J$ and $w, z \in C(J), \phi(w(\varsigma), z(\varsigma)) \geq 0$ implies

$$
\phi\left(\int_{0}^{1} \mathbb{G}(\zeta, \vartheta) h(\vartheta, w(\vartheta)) d \vartheta, \int_{0}^{1} \mathbb{G}(\zeta, \vartheta) h(\vartheta, z(\vartheta)) d \vartheta\right) \geq 0
$$

(iv) if $\left\{w_{n}\right\} \subseteq C(J), w_{n} \rightarrow w$ in $C(J)$, and $\phi\left(w_{n}, w_{n+1}\right) \geq 0$, then $\phi\left(w_{n}, w\right) \geq 0$ for all $n$.

Then the problem (7) has at least one solution.

Proof. By employing (8) and in accordance with 3, we obtain

$$
\begin{aligned}
|A w(\varsigma)-A z(\varsigma)|^{2} & \leq\left[\int_{0}^{1} \mathbb{G}(\varsigma, \vartheta)|h(\varsigma, w(\varsigma))-h(\varsigma, z(\varsigma))| d \vartheta\right]^{2} \\
& \leq\left[\int_{0}^{1} \mathbb{G}(\varsigma, \vartheta) \frac{\Gamma(v+1)}{2 \sqrt{2}} \sqrt{\psi\left(\left\|(w-z)^{2}\right\|_{\infty}\right) \lambda\left(\psi\left(\left\|(w-z)^{2}\right\|_{\infty}\right)\right)} d \vartheta\right]^{2} .
\end{aligned}
$$

The rest of proof is similar to that of Theorem 3.

\section{Conclusion}

In this paper, we discuss some more general form of the fractional differential equation. compare to the related literatures the presented results here are more general. For example, the equation in [10], is in the form of a nonlinear fractional differential equation of order $\alpha$, $3 \leq \alpha \leq 4$. On the other hand, the equation introduced here is a nonlinear fractional differential equation of orders $\mu$ and $v, 0<v<\mu$, where these numbers are arbitrary.

Most of results in the mentioned papers in the reference section can be considered only by setting $\mu=0$ or $v=0$. Only in the presented case one can obtain an equation of order $\mu$ or $v$. In the other words, most articles can be considered as a spacial case of the presented equation. In addition, the conditions and hypotheses presented in the theorems of this article are more general than the previous articles. For instance, in [10, Theorem 2.3], it was considered $\lambda(t)=\lambda /(1+4 \lambda)$. Here, in this present article, we consider the most general form: we consider $\lambda$ as an arbitrary function belonging to $\Lambda$.

Besides all differences, as we mentioned above, the integral equation equivalent to the differential equation in [10] has a Green function whose upper and lower boundaries are given, while here the integral equation is equivalent to the differential equation in [10, Theorem 2.3] has no Green function. 


\section{Acknowledgements}

The authors thanks anonymous referees for their remarkable comments, suggestion, and ideas that help to improve this paper.

\section{References}

[1] Abdeljawad T., Agarwal R.P., Karapinar E., Kumari P.S. Solutions of he nonlinear integral equation and fractional differential equation using the technique of a fixed point with a numerical experiment in extended b-metric space. Symmetry 2019, 11 (5), 686. doi:10.3390/sym11050686

[2] Acar O. Generalization of $\left(\alpha-F_{d}\right)$-contraction on quasi metric space. Commun. Fac. Sci. Univ. Ank. Ser. A1 Math. Stat. 2019, 68 (1), 35-42. doi:10.31801/cfsuasmas.443587

[3] Adigüzel R.S., Aksoy Ü., Karapinar E., Erhan I.M. On the solution of a boundary value problem associated with a fractional differential equation. Math. Methods Appl. Sci. 2020. doi:10.1002/mma.6652

[4] Alqahtani B., Aydi H., Karapinar E., Rakocevic V. A Solution for Volterra Fractional Integral Equations by Hybrid Contractions. Mathematics 2019, 7 (8), 694. doi:10.3390/math7080694

[5] Afshari H., Alsulami H.H., Karapinar E. On the extended multivalued Geraghty type contractions. J. Nonlinear Sci. Appl. 2016, 9 (6), 4695-4706. doi:10.22436/jnsa.009.06.108

[6] Afshari H., Aydi H., Karapinar E. On generalized $\alpha-\psi$-Geraghty contractions on b-metric spaces. Georgian Math. J. 2018, 27 (1), 9-21. doi:10.1515/gmj-2017-0063

[7] Afshari H., Aydi H., Karapinar E.Existence of fixed points of set-valued mappings in b-metric spaces. East Asian Math. J. 2016, 32 (3), 319-332. doi:10.7858/eamj.2016.024

[8] Afshari H., Baleanu D. Applications of some fixed point theorems for fractional differential equations with MittagLeffler kernel. Adv. Difference Equ. 2020, 2020, 140. doi:10.1186/s13662-020-02592-2

[9] Afshari H., Kalantari S., Karapinar E. Solution of fractional differential equations via coupled FP. Electron. J. Differential Equations 2015, 2015 (286), 1-12.

[10] Afshari H., Kalantari S., Baleanu D. Solution of fractional differential equations via $\alpha-\psi$-Geraghty type mappings. Adv. Difference Equ. 2018, 2018, 347. doi:10.1186/s13662-018-1807-4

[11] Bota M.-F., Chifu C., Karapinar E. Fixed point theorems for generalized $(\alpha-\psi)$-Ciric-type contractive multivalued operators in b-metric spaces. J. Nonlinear Sci. Appl. 2016, 9 (3), 1165-1177.

[12] Bota M.-F., Karapinar E., Mlesnite O. Ulam-Hyers stability results for fixed point problems via alpha-psi-contractive mapping in b-metric space. Abstr. Appl. Anal. 2013, 2013, 825293. doi:10.1155/2013/825293

[13] Babu A.S., Došenović T., Ali Md. M., Radenović S., Rao K.P.R. Some Prešić type results in b-dislocated metric spaces. Constr. Math. Anal. 2019, 2 (1), 40-48. doi:10.33205/cma.499171

[14] Chifu C. Common fixed point results in extended b-metric spaces endowed with a directed graph. Res. Nonlinear Anal. 2019, 2 (1), 18-24.

[15] Öztürk A. A fixed point theorem for mappings with an F-contractive iterate. Adv. Theory Nonlinear Anal. Appl. 2019, 3 (4), 231-235. doi:10.31197/atnaa.644325

[16] Gülyaz-Özyurt S. A fixed point theorem for extended large contraction mappings. Res. Nonlinear Anal. 2018, 1 (1), $46-48$.

[17] Gülyaz-Özyurt S. On some $\alpha$-admissible contraction mappings on Branciari b-metric spaces. Adv. Theory Nonlinear Anal. Appl. 2017, 1 (1), 1-13. doi:10.31197/atnaa.318445

[18] Nashine H.K., Gupta A., Agarwal R. P. Positive solutions of nonlinear fractional differential equations in non-zero self-distance spaces. Georgian Math. J. 2017, 24 (4), 545-569. doi:10.1515/gmj-2017-0040

[19] Kadelburg Z., Radenović S. Notes on some recent papers concerning F-contractions in b-metric spaces. Georgian Math. J. 2018, 1 (2), 108-112. doi:10.33205/cma.468813 
[20] Karapinar E., Aydi H., Mitrović Z.D. On interpolative Boyd-Wong and Matkowski type contractions. TWMS J. Pure Appl. Math. 2020, 11 (2), 204-212.

[21] Karapinar E. A short survey on the recent fixed point results on b-metric spaces. Constr. Math. Anal. 2018, 1 (1), 15-44. doi:10.33205/cma.453034

[22] Karapinar E., Chen C.-M., Fulga A. Nonunique coincidence point results via admissible mappings. J. Funct. Spaces 2021, 2021, 5538833. doi:10.1155/2021/5538833.

[23] Karapinar E., Fulga A., Rashid M., Shahid L., Aydi H. Large contractions on quasi-metric spaces with an application to nonlinear fractional differential equations. Mathematics 2019, 7 (5), 444. doi:10.3390/math7050444

[24] Karapinar E., Samet B. Generalized $\alpha$ - $\psi$-contractive type mappings and related fixed point theorems with applications. Abstr. Appl. Anal. 2012, 2012, 793486. doi:10.1155/2012/793486

[25] Kilbas A.A., Srivastava H.M., Trujillo J.J. Theory and Applications of Fractional Differential Equations. North-Holland Mathematics Studies, Elsevier, Amsterdam, 2006.

[26] Marasi H.R., Afshari H., Daneshbastam M., Zhai C.B. Fixed points of mixed monotone operators for existence and uniqueness of nonlinear fractional differential equations. J. Contemp. Math. Anal. 2017, 52, 8-13. doi:10.3103/S1068362317010022 (translation of Izv. Nats. Akad. Nauk Armenii Mat. 2017, 1, 78-84. (in Russian))

[27] Nazam M., Arshad M., Park C., Acar Ö., Yun S., Anastassiou G. A. On solution of a system of differential equations via fixed point theorem. J. Comput. Anal. Appl. 2019, 27 (3), 417-426.

[28] Eloe P.W., Jonnalagadda J. Quasilinearization and boundary value problems for riemann-liouville fractional differential equations. Electron. J. Differential Equations 2019, 2019 (58), 1-15.

[29] Podlubny I. Fractional Differential Equations. Academic Press, San Diego, 1999.

[30] Roshan J.R., Parvaneh V., Sedghi S., Shobkolaei N., Shatanawi W. Common fixed points of almost generalized $(\alpha, \psi)_{s}$-contractive mappings in ordered b-metric spaces. Fixed Point Theory Appl. 2013, $2013,159$. doi:10.1186/1687-1812-2013-159

[31] Samet B., Vetro C., Vetro P. Fixed point theorems for $\alpha$ - $\psi$-contractive type mappings. Nonlinear Anal. 2012, 75 (4), 2154-2165. doi:10.1016/j.na.2011.10.014

[32] Zhu T. Existence and uniqueness of positive solutions for fractional differential equations. Bound. Value Probl. 2019, 2019, 22. doi:10.1186/s13661-019-1141-0

Received 13.03.2021

Revised 11.04.2021

Афшарі Г., Карапінар Е. Розв'язок дробових диференціальних рівнянь, визначених у b-метричному просторі // Карпатські матем. публ. - 2021. - Т.13, №3. - С. 764-774.

У цій роботі ми вивчаємо існування розв'язків наступних диференціальних рівнянь за допомогою теорем про нерухому точку

$$
\left\{\begin{array}{l}
D_{c}^{\mu} w(\varsigma) \pm D_{c}^{v} w(\varsigma)=h(\varsigma, w(\varsigma)), \quad \varsigma \in J, \quad 0<v<\mu<1 \\
w(0)=w_{0},
\end{array}\right.
$$

де $D^{\mu}, D^{v}$ - похідна Капуто порядку $\mu, v$ відповідно і відображення $h: J \times \mathbb{R} \rightarrow \mathbb{R}$ неперервне. Результати добре підкріплені цікавими прикладами.

Ключові слова і фрази: повний $b$-метричний простір, похідна Капуто, $\alpha$ - $\psi$-відображення скорочувального типу $\Delta$ жераті. 